\title{
Physician's feedback on a clinical pharmacy program on geriatric wards
}

\author{
Julie Hias $\mathbb{D}^{* a}$, Karolien Walgraeve*a, Jos Tournoy ${ }^{\mathrm{b}, c}$, Johan Flamaing ${ }^{\mathrm{b}, \mathrm{c}}$, Isabel Spriet ${ }^{\mathrm{a}, \mathrm{d}}$ \\ and Lorenz Van der Linden (iD) ${ }^{\text {a,d }}$

\begin{abstract}
aPharmacy Department, University Hospitals Leuven, Leuven, Belgium; 'Department of Geriatric Medicine, University Hospitals Leuven, Leuven, Belgium; 'Department of Chronic Diseases, Metabolism and Ageing, KU Leuven, Leuven, Belgium; dDepartment of Pharmaceutical and Pharmacological Sciences, KU Leuven, Leuven, Belgium
\end{abstract}

\section{ABSTRACT}

Objectives: As clinical pharmacy (CP) services can improve drug use and clinical outcome in older inpatients, a dedicated CP program was installed at the geriatric wards of an academic hospital. The aim of this study was to evaluate and potentially improve the CP program, by obtaining physician's feedback.

Methods: An anonymous e-questionnaire was sent to all physicians who were active between October 2014 and March 2018 on the acute geriatric wards (80 beds) of the University Hospitals Leuven, Belgium. Thematic content analysis was applied. Six themes were defined: satisfaction with the service, time allocation of the clinical pharmacists, content and clinical relevance of pharmaceutical interventions, communication, time savings for the treating physician and future perspectives.

Results: A total of 45 physicians (59\%) completed the e-questionnaire. All respondents were satisfied with the content of the provided pharmaceutical recommendations. A minority (44\%) found that a 0.8 full-time equivalent clinical pharmacist presence was sufficient in terms of the expected workload. The provided CP interventions improved quality of care according to $38(84 \%)$ physicians. Oral and written communication were considered necessary by $89 \%$ and $82 \%$ of physicians, respectively. On average, an estimated 30 minutes physician time (IQR: 15-60) per patient was saved as a result of the program. The majority (87\%) preferred clinical pharmacist presence for discharge support in all geriatric patients.

Conclusion: Physician's satisfaction with the $\mathrm{CP}$ service was very high. $\mathrm{CP}$ services in geriatric inpatients were perceived to be clinically relevant as well as time-saving by the involved physicians.

\section{KEYWORDS}

Clinical pharmacy service; geriatric inpatients; physician's feedback; Hospital pharmacists; Belgium

\section{Introduction}

Drug-related problems (DRP) remain prevalent and can cause actual harm in older patients, particular in older inpatients, which can in part be explained by the high rates of polypharmacy and inappropriate prescribing $[1,2]$. Harmful DRP occur more often in older adults than in younger adults and also lead to more unplanned admissions to the hospital, of which a part is most likely avoidable [3]. Older adults are considered to be increasingly susceptible to such DRP owing to, among others, age-related depletion of the physiological reserve, presence of multimorbidity and a multitude of involved prescribers [4-7]. Frequently, single-disease clinical practice guidelines are followed when prescribing drugs. Many of these guidelines do not include specific recommendations on how to appropriately prescribe drugs in these multimorbid complex older adults [8]. In sum, older inpatients constitute a high risk group in terms of drug-related harm and are hence deserving of targeted interventions.

Pharmacist-led interventions, most commonly based on providing a structured medication review, appear beneficial in terms of improving drug use and reducing DRP in older patients [9-15]. Clinical pharmacy (CP) interventions have also been shown to reduce hospital visits in a cost-effective manner, yet findings of several ongoing large-scale investigations are awaited to allow for more robust claims concerning clinical benefit [16-18]. Several clinical pharmacy projects were piloted in Belgium in 2007. These pilot projects generated positive results and the federal government subsequently converted the pilot funding into structural funding from 2014 on. This governmental funding supports a 0.125 full time equivalent (FTE) clinical pharmacists per 100 beds [19].

Based upon the body of evidence and our own investigations, a CP program was installed in 2014 on the acute geriatric care wards of the University Hospitals Leuven, Belgium [2,20-22]. The CP program entailed providing medication reviews during hospital stay, with a major aim to optimize prescribing and provide a correct and patient friendly medication list at the moment of actual hospital discharge [23]. In order to evaluate the $\mathrm{CP}$ program in a qualitative 
manner, we wanted feedback from the prescriber. Such information might allow for further improvement of the program in terms of communication, content and time allocation.

\section{Methods}

A CP program was installed as of October 2014 on the 80-bed acute geriatric care wards of the University Hospitals Leuven, Belgium. The overall approach of the program was based on the Lund Integrated Medicines Management (LIMM) model [24]. The CP program consisted of a multicomponent intervention which entailed medication reconciliation (upon physician's request), medication review on admission, during hospitalization and/or at discharge, solving patientbased pharmacotherapeutic questions and providing patient-friendly medication lists. Funding was provided for a 0.8 FTE mandate, covering 80 beds on three acute geriatric care wards. There were three clinical pharmacists (KW, JH, LVDL) involved in this 0.8 FTE mandate. First temporary funding was provided by the hospital board, which later became permanent at the end of 2018. Since the mandate did not meet the clinical demand to cover all of the above interventions for all patients, the program focused on medication reconciliation and review at discharge. A structured pharmacy form (see Appendix 1), incorporated into the electronic health record (EHR) of the patient, was developed for documenting the type of recommendation, involved drug classes and acceptance of the proposed recommendations. Furthermore, pharmaceutical recommendations were also communicated orally to the treating physicians.

An anonymous e-questionnaire (see Appendix 2) was developed using Google Forms and sent via e-mail to all physicians who worked on the acute geriatric wards between October 2014 and March 2018. These include staff geriatricians, and both resident physicians in training for internal medicine or geriatrics. The questionnaire was sent on March $27^{\text {th }}$ and terminated on 2 May 2018. Two reminders were sent, after two and four weeks.

Initial questions were drafted by the CP group (KW, $J H, I S, L V D L)$ and were then discussed with involved geriatricians (JF, JT), until full consensus was reached. Questions were considered to be valid if they accounted for physician's satisfaction and feedback relating to the allocated CP mandate. Physician's satisfaction or agreement was determined using a five-point Likert-scale. Physician's feedback was also collected using open-ended (e.g. the estimated amount of time saved by the pharmacist) and multiple choice questions. Each question included an option to provide additional remarks.

Thematic content analysis was performed by two investigators $(\mathrm{JH}, \mathrm{KW})$. Following major themes were defined: satisfaction with the service, time allocation of the clinical pharmacists, content and clinical relevance of pharmaceutical interventions, communication, time savings for the treating physician and future perspectives. Answers were grouped and recoded in order to provide semi-quantitative output, independently by two investigators (JH, KW). Discrepancies were presented to a third investigator (LVDL) and consensus was reached for the interpretation of all answers.

Normality for the amount of time saved by the clinical pharmacist (expressed in minutes) was determined by visual inspection of the histograms and by formal testing (i.e. Kolgomorov Smirnov test) and was expressed as median and interquartile ranges (IQR: Q1, Q3). Categorical data were summarized as counts and percentages. A Fisher Exact test was used to compare the responses for the overall satisfaction of the clinical pharmacy service and the 0.8 FTE allocation according to the level of professional experience. Both responses were selected, given their overall importance in this survey. Statistical tests were not performed for all statements, as the resulting $p$-values would not be informative, owing to multiple comparisons for which no formal sample size estimation was done beforehand. It has been recommended to limit such inferential testing to a minimum to render found results more valid $[25,26]$.

Data were retrieved from Google Forms and collected in 'Statistical Package for the Social Sciences' (SPSS) version 25.

\section{Results}

Between October 2014 and March 2018, 69 physicians and 7 staff geriatricians worked on the acute geriatric care wards of the University Hospitals Leuven, Belgium. Clinical pharmacy interventions were provided in $67.5 \%$ of patients who had been admitted to the acute geriatric care ward in 2017.

Answers were retrieved from 45 physicians (59\%), comprising 3 staff geriatricians and 15 senior physicians in training (i.e. year 4-6 of 6 years training in geriatric medicine). The remainder, $27(60 \%)$ physicians, concerned junior physicians in training (i.e. year 1-3 of 6 years training in internal medicine).

\section{Satisfaction with the service}

Satisfaction with the overall delivered $\mathrm{CP}$ service was very high: $76 \%$ of physicians were very satisfied, $22 \%$ were satisfied and $2 \%$ were neutral. The distribution according to physician's level of experience is shown in Figure 1. According to the level of professional experience, no statistical significant difference was found between the three prescriber groups $(p=0.172)$. All physicians were satisfied with the content of the provided pharmaceutical recommendations; $69 \%$ were very satisfied. 


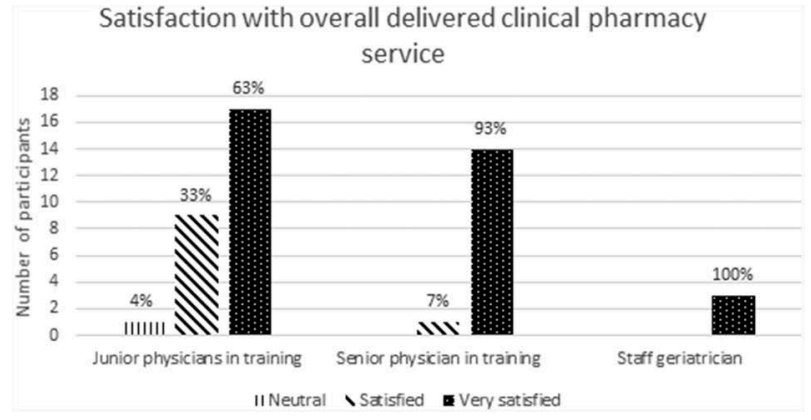

Figure 1. Satisfaction with overall delivered clinical pharmacy service according to physician's experience.

\section{Time allocation of the clinical pharmacists}

In Figure 2 the opinion of the physicians concerning time allocation of the 0.8 FTE CP service has been presented. Figure 3 shows the response to whether 0.8 FTE was enough, according to the physician's level of experience. No statistical significant difference was found $(p=0.091)$.

\section{Content and perceived clinical relevance of pharmaceutical interventions}

All physicians agreed that the recommendations proposed by the clinical pharmacists were evidence-based (78\% strongly agreed, $22 \%$ agreed) and that the preparation of a patient-friendly discharge medication list was an added value (80\% strongly agreed, $20 \%$ agreed). The majority indicated that they regularly accepted the

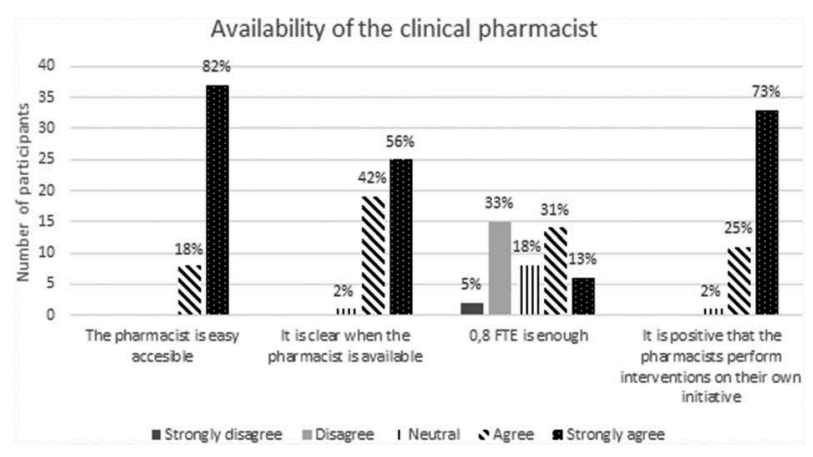

Figure 2. Availability of the clinical pharmacist.

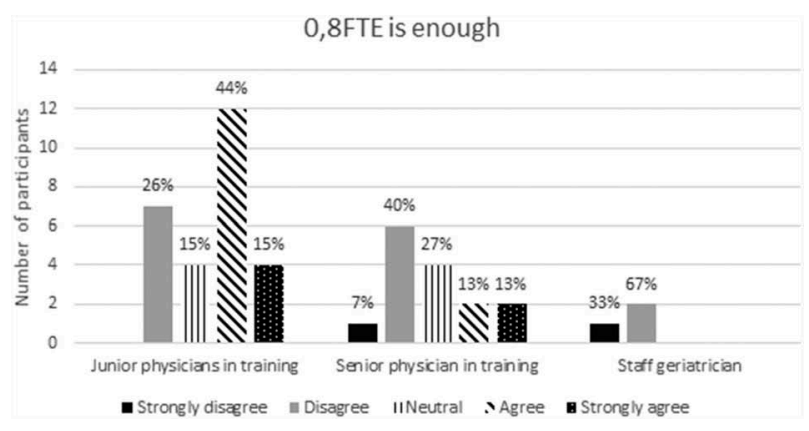

Figure 3. Physician's opinion about time allocation according to their experience. proposed recommendations (60\% strongly agreed, 33\% agreed, $7 \%$ voted neutral), that the recommendations were generally an added value (69\% strongly agreed, $29 \%$ agreed, $2 \%$ voted neutral). Respondents stated that the written recommendations were specific and that a clear pharmaceutical plan was normally offered (49\% strongly agreed, $40 \%$ agreed, $11 \%$ voted neutral).

The added value of the $\mathrm{CP}$ service according to the physicians is displayed in Table 1.

\section{Communication}

Figure 4 displays statements on the communication modalities which the $\mathrm{CP}$ team applies to provide pharmaceutical recommendations. The added value of selected communication methods, as perceived by the questionnaire respondents, has been presented in Table 2.

\section{Time savings for the treating physician}

None of the physicians disagreed that the availability of a ward-based clinical pharmacist in the multidisciplinary geriatric team is time-saving; $78 \%$ strongly agreed, $18 \%$ agreed and $4 \%$ were neutral. According to the physicians, the clinical pharmacists saved on average 30 min (IQR: 15-60) per patient. Components, where $\mathrm{CP}$ services were deemed time-saving, have been summarized in Table 3.

\section{Future perspectives}

Physicians responded that medication review at discharge $(n=35 ; 78 \%)$ should remain a priority of the CP team, followed by the preparation of a patient-friendly discharge medication list $(n=30 ; 67 \%)$, medication review and medication reconciliation on admission $(n=29 ; 64 \%)$, patient counseling at discharge $(n=14$; $31 \%)$ and contact by phone with the general practitioner about therapy changes and recommendations after discharge $(n=4 ; 9 \%)$. None chose physical participation in the daily patient rounds. Results concerning suggestions to improve the program in the near future can be found in Figure 5 .

\section{Discussion}

A CP program was installed on the geriatric wards of a large teaching hospital in the aftermath of several investigations $[2,21,22]$. In order to evaluate and further improve the care delivery, physician's feedback was obtained through an e-questionnaire. The overall program was scored positively by all respondents and the perception of its relevance was found to be independent of the physician's level of experience. A trend towards more positive responses was found in favor of the most experienced respondents. 
Table 1. Added value of clinical pharmacy services.

\begin{tabular}{|c|c|c|c|c|}
\hline $\begin{array}{l}\text { ADDED VALUE OF PHARMACEUTICAL RECOMMENDATIONS } \\
\text { (multiple options permitted) }\end{array}$ & $\begin{array}{l}\text { Number of total } \\
\text { respondents that } \\
\text { concurred with } \\
\text { the statement (n } \\
(\%))\end{array}$ & $\begin{array}{l}\text { Number of junior } \\
\text { physicians in train- } \\
\text { ing that concurred } \\
\text { with the statement } \\
(\mathrm{n}(\%))\end{array}$ & $\begin{array}{l}\text { Number of senior } \\
\text { physicians in train- } \\
\text { ing that concurred } \\
\text { with the statement } \\
\text { (n (\%)) }\end{array}$ & $\begin{array}{l}\text { Number of staff } \\
\text { geriatricians that } \\
\text { concurred with } \\
\text { the statement } \\
(\mathrm{n}(\%))\end{array}$ \\
\hline It improves the quality of patient care & $38(84 \%)$ & $20(74 \%)$ & $15(100 \%)$ & $3(100 \%)$ \\
\hline It is time-saving & $35(78 \%)$ & $22(82 \%)$ & $10(67 \%)$ & $3(100 \%)$ \\
\hline Relevant information is gained & $34(76 \%)$ & $17(63 \%)$ & $14(93 \%)$ & $3(100 \%)$ \\
\hline $\begin{array}{l}\text { The presence of the pharmacist makes me more aware of drug } \\
\text { therapy }\end{array}$ & $31(69 \%)$ & $18(67 \%)$ & $11(80 \%)$ & $2(67 \%)$ \\
\hline It supports the physicians on the ward & $31(69 \%)$ & $16(59 \%)$ & $12(80 \%)$ & $3(100 \%)$ \\
\hline latrogenic damage is avoided & $20(44 \%)$ & $10(37 \%)$ & $8(53 \%)$ & $2(67 \%)$ \\
\hline Otherwise there is no time to perform the same intervention & $20(44 \%)$ & $13(48 \%)$ & $6(40 \%)$ & $1(33 \%)$ \\
\hline $\begin{array}{l}\text { The recommendations are useful, however I would have come to it } \\
\text { on my own }\end{array}$ & $3(7 \%)$ & $2(7 \%)$ & $1(7 \%)$ & $0(0 \%)$ \\
\hline No added value & $0(0 \%)$ & $0(0 \%)$ & $0(0 \%)$ & $0(0 \%)$ \\
\hline \multicolumn{5}{|l|}{$\begin{array}{l}\text { ADDED VALUE OF PREPARING A PATIENT-FRIENDLY DISCHARGE } \\
\text { MEDICATION SCHEME }\end{array}$} \\
\hline Instructions are added & $37(82 \%)$ & $21(78 \%)$ & $13(87 \%)$ & $3(100 \%)$ \\
\hline Indications for new drugs are added & $32(71 \%)$ & $19(70 \%)$ & $11(73 \%)$ & $2(67 \%)$ \\
\hline It is time-saving & $30(67 \%)$ & $18(67 \%)$ & $11(73 \%)$ & $1(33 \%)$ \\
\hline Changes are described & $28(62 \%)$ & $15(56 \%)$ & $11(73 \%)$ & $2(67 \%)$ \\
\hline Substitution is taken into account at discharge & $28(62 \%)$ & $15(56 \%)$ & $10(67 \%)$ & $3(100 \%)$ \\
\hline No added value & $0(0 \%)$ & $0(0 \%)$ & $0(0 \%)$ & $0(0 \%)$ \\
\hline
\end{tabular}

It is important to acknowledge however that such testing was not predefined. All results should hence be interpreted as solely hypothesis-generating. It is reassuring however that experience did not

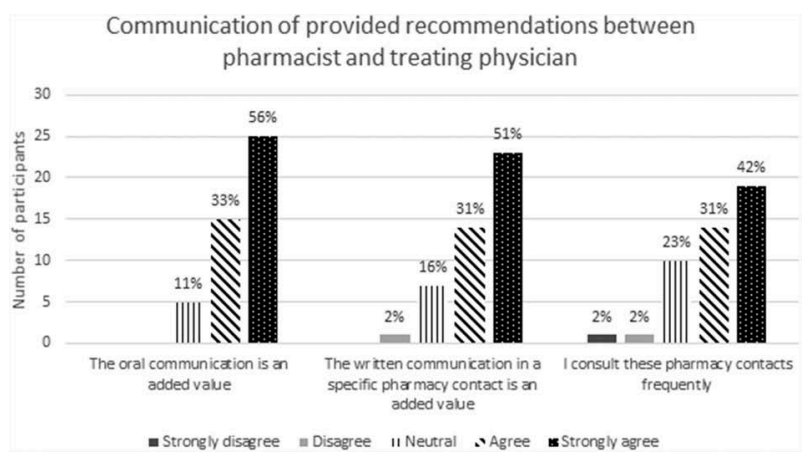

Figure 4. Type of communication of the pharmaceutical recommendations by the clinical pharmacists. negatively impact the evaluation of the CP service. Regarding the actual drug-related content of the provided recommendations, all physicians were satisfied, which translated into a high acceptance rate of approximately $80 \%$ in daily practice. Acceptance of pharmacist provided recommendations was evaluated during the individual discussions with the treating physicians.

Without performing a randomized controlled trial (or a valid alternative), it is impossible to draw robust conclusions regarding the actual clinical benefit of the CP program or to infer whether the prescribers would have eventually changed the prescriptions themselves. Nonetheless, in this survey it was assumed by a large majority (84\%) that the CP program effectively improved individual patient care. Several studies have already shown that pharmacist-led interventions can reduce inappropriate prescribing. Multifaceted interventions,

Table 2. Added value of different communication methods.

\begin{tabular}{|c|c|c|c|c|}
\hline $\begin{array}{l}\text { ADDED VALUE OF ORAL COMMUNICATION } \\
\text { (multiple options permitted) }\end{array}$ & $\begin{array}{l}\text { Number of total } \\
\text { respondents that } \\
\text { concurred with } \\
\text { the statement (n } \\
(\%) \text { ) }\end{array}$ & $\begin{array}{l}\text { Number of junior } \\
\text { physicians in train- } \\
\text { ing that concurred } \\
\text { with the statement } \\
\text { (n (\%)) }\end{array}$ & $\begin{array}{l}\text { Number of senior } \\
\text { physicians in train- } \\
\text { ing that concurred } \\
\text { with the statement } \\
(\mathrm{n}(\%))\end{array}$ & $\begin{array}{l}\text { Number of staff } \\
\text { geriatricians that } \\
\text { concurred with } \\
\text { the statement } \\
(\mathrm{n}(\%))\end{array}$ \\
\hline It gives the opportunity to ask additional questions & $40(88 \%)$ & $25(93 \%)$ & $13(87 \%)$ & $2(67 \%)$ \\
\hline $\begin{array}{l}\text { It gives the opportunity to discuss why a recommendation cannot } \\
\text { be followed }\end{array}$ & $30(67 \%)$ & $15(56 \%)$ & $13(87 \%)$ & $2(67 \%)$ \\
\hline $\begin{array}{l}\text { No added value, I consult the written recommendations in the } \\
\text { pharmacy consult }\end{array}$ & $3(7 \%)$ & $2(7 \%)$ & $1(7 \%)$ & $0(0 \%)$ \\
\hline No added value, no extra information is given & $0(0 \%)$ & $0(0 \%)$ & $0(0 \%)$ & $0(0 \%)$ \\
\hline No added value, it is too time consuming & $0(0 \%)$ & $0(0 \%)$ & $0(0 \%)$ & $0(0 \%)$ \\
\hline \multicolumn{5}{|l|}{$\begin{array}{l}\text { ADDED VALUE OF WRITTEN PHARMACY CONSULT IN ELECTRONIC } \\
\text { PATIENT HEALTH RECORD }\end{array}$} \\
\hline The recommendations can be consulted on a later moment & $34(76 \%)$ & $20(74 \%)$ & $11(73 \%)$ & $3(100 \%)$ \\
\hline $\begin{array}{l}\text { The therapy changes (that occurred during hospitalization) are } \\
\text { summed up and can be copied in the discharge letter }\end{array}$ & $26(58 \%)$ & $12(44 \%)$ & $11(73 \%)$ & $3(100 \%)$ \\
\hline $\begin{array}{l}\text { The recommendations can be copied in the discharge letter to the } \\
\text { general practitioner }\end{array}$ & $25(56 \%)$ & $12(44 \%)$ & $11(73 \%)$ & $2(67 \%)$ \\
\hline $\begin{array}{l}\text { The references where the recommendations were based on are } \\
\text { reported and can be consulted }\end{array}$ & $20(44 \%)$ & $8(30 \%)$ & $10(67 \%)$ & $2(67 \%)$ \\
\hline No added value, I never consult the written recommendations & $0(0 \%)$ & $0(0 \%)$ & $0(0 \%)$ & $0(0 \%)$ \\
\hline
\end{tabular}


Table 3. Reasons why clinical pharmacists are time-saving (multiple options permitted).

\begin{tabular}{|c|c|c|c|c|}
\hline & $\begin{array}{l}\text { Number of total } \\
\text { respondents that con- } \\
\text { curred with the state- } \\
\text { ment }(\mathrm{n}(\%))\end{array}$ & $\begin{array}{l}\text { Number of junior physicians } \\
\text { in training that concurred } \\
\text { with the statement (n (\%)) }\end{array}$ & $\begin{array}{l}\text { Number of senior physi- } \\
\text { cians in training that con- } \\
\text { curred with the statement } \\
(\mathrm{n}(\%))\end{array}$ & $\begin{array}{l}\text { Number of staff geria- } \\
\text { tricians that concurred } \\
\text { with the statement } \\
(\mathrm{n}(\%))\end{array}$ \\
\hline $\begin{array}{l}\text { Preparation of the discharge } \\
\text { medication list }\end{array}$ & $42(93 \%)$ & $24(89 \%)$ & $15(100 \%)$ & $3(100 \%)$ \\
\hline $\begin{array}{l}\text { Medication reconciliation on } \\
\text { admission }\end{array}$ & $39(87 \%)$ & $21(78 \%)$ & $15(100 \%)$ & $3(100 \%)$ \\
\hline $\begin{array}{l}\text { Clarification of pharmaceutical } \\
\text { problems/questions }\end{array}$ & $35(78 \%)$ & $18(67 \%)$ & $14(93 \%)$ & $3(100 \%)$ \\
\hline $\begin{array}{l}\text { Summary of medication changes } \\
\text { that occurred during the } \\
\text { hospitalization }\end{array}$ & $34(76 \%)$ & $18(67 \%)$ & $13(87 \%)$ & $3(100 \%)$ \\
\hline Comprehensive medication review & $31(69 \%)$ & $16(59 \%)$ & $13(78 \%)$ & $2(67 \%)$ \\
\hline $\begin{array}{l}\text { Support with the administration for } \\
\text { reimbursements }\end{array}$ & $23(51 \%)$ & $12(44 \%)$ & $9(60 \%)$ & $2(67 \%)$ \\
\hline $\begin{array}{l}\text { The availability of a clinical } \\
\text { pharmacist is not time-saving }\end{array}$ & $0(0 \%)$ & $0(0 \%)$ & $0(0 \%)$ & $0(0 \%)$ \\
\hline
\end{tabular}

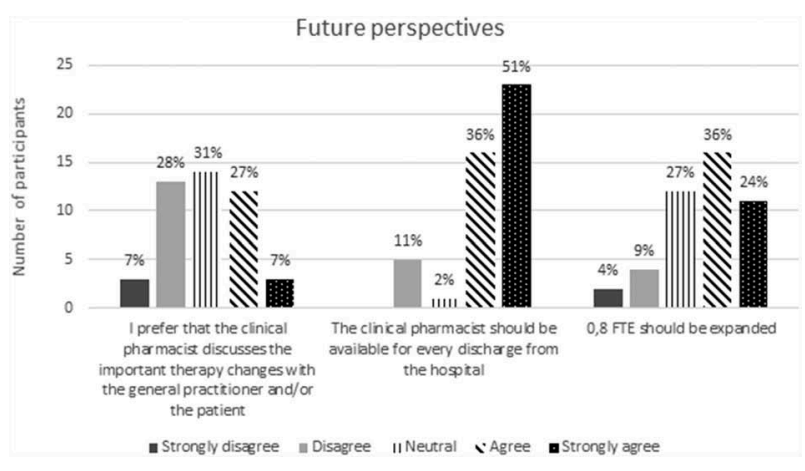

Figure 5. Future perspectives according to the physicians.

such as the one implemented in this study, have even been able to show a reduction in hospital readmissions and emergency department contacts $[2,16,17,27]$. Furthermore, clinical pharmacists were considered to be valuable team members, as only $7 \%$ of the physicians stated that they would have come to the same therapy alterations themselves. A study performed on the same acute geriatric wards in 2012 showed that, compared with usual care, i.e. without involvement of clinical pharmacists, on average more potentially inappropriate drugs were discontinued or reduced in dose in the intervention group, i.e. with involvement of a clinical pharmacist [usual care vs. intervention: 1 (IQR: 1-2) vs. 2 (IQR: 1-4); $p=0.003$ ] [2].

In our program, pharmaceutical recommendations are currently communicated to the treating physicians orally as well as written in a structured form that is incorporated into the EHR. Both oral and written communication appeared useful to share pharmaceutical recommendations with the treating physicians. The written electronic pharmacy consult proves to be a useful communication tool for pharmaceutical recommendations for a majority of the respondents $(82 \%)$. It allows for the recommendations to be consulted on a later time point and to be easily adopted in the discharge letter to the general practitioner. Almost three quarters (73\%) of the physicians stated to frequently consult the written recommendations. The face-to-face consultation between the clinical pharmacist and treating physician was equally considered to be a valuable way of communicating the pharmaceutical recommendations (89\%). A possible explanation is that the latter approach offers more room for interdisciplinary discussion and additional questions, hence resulting in a team-based decision.

Clinical pharmacists were perceived to be time-saving. Since the clinical pharmacist provided on average at least 1 intervention for 6 patients (IQR: 4-9) per working day (i.e. 3 hours saved per day), this would mean that on average 12 physician hours are saved weekly with a 0.8 FTE presence for a same level of care. Time could have been saved by nearly all of the CP activities, such as by preparing a patient-friendly discharge drug scheme or by performing a comprehensive medication review. It stands to reason that pharmacist involvement might result in time and subsequent financial gains, given that pharmacists mostly perform activities for a lower wage than prescribers with at least the same amount of quality [28]. Other investigations have already pointed toward the potential cost-effectiveness of clinical pharmacists, mainly due to reductions in incident unplanned readmissions to the hospital $[16,17,27]$. Time savings might add to the financial impact of CP programs within the hospital and deserves to be further scrutinized in future investigations.

Physicians preferred that clinical pharmacists invested their time predominantly in medication review at discharge, which was in line with the strategical plan of the CP program. Some physicians suggested that more benefit could be expected if these recommendations were provided earlier on during hospital stay. Most physicians however would like to increase the overall involvement of clinical pharmacists, i.e. both on admission and at discharge from the hospital. For instance an increased focus on medication reconciliation on admission could be beneficial, since polypharmacy and older age are determinants for discrepancies in preadmission drug 
lists [29]. Cornu et al also observed that discrepancies on admission may be associated with at least half of the discrepancies at discharge [30]. Performing medication reconciliation for every admitted patient to our geriatric wards has however been found to be difficult to impossible within the current mandate. Currently, the CP program provides pharmaceutical care upon discharge in approximately two-thirds of geriatric inpatients. Hence, the majority of the physicians concluded that 0.8 FTE for 80 beds should be expanded in the future.

Regarding the future perspective, a minority of the participants (34\%) were also in favor of incorporating patient counseling into the workflow of the $\mathrm{CP}$ team as well as directly communicating with the general practitioner. This low positive response rate could be in part be explained by our experience that many physicians believe that they should be the ones performing the counseling, while also directly providing information to the patient's GP. Importantly, there is current evidence however that pharmacist-supported transitional care can further improve outcome. The need to expand CP activities beyond discharge has recently been supported by several research groups. Pellegrin et al and Ravn-Nielsen et al have proposed to apply motivational interviews, including patient education and follow-up with primary care to ensure optimal drug therapies during transitions of care $[17,27]$. Collaboration with primary care is crucial a) to ascertain the best possible pre-admission list, b) to verify whether there were any previously (un)reported drug-related problems and c) to reach a consensus between healthcare professionals on the best possible therapy after discharge for the individual patient.

Some physicians suggested to focus only on high risk patients, based on e.g. their clinical suspicion. Currently, however, it is not possible to objectively define subsets of higher risk geriatric inpatients. To the best of our knowledge, the highest risk is attained by being admitted to the geriatric care unit. Some respondents suggested to primarily direct the limited resources towards geriatric patients admitted to nongeriatric wards. We do not disagree with this viewpoint in and of itself. Importantly, such non-geriatric wards however often lack a dedicated geriatric team. Also, given the current state of evidence, it remains important to acknowledge that there is currently more data in support of providing CP services in a dedicated (for geriatric patients) and team-based setting, such as is provided on acute geriatric care wards [31]. Conversely, up to now it is not robustly proven that a liaison approach of the internal geriatric consultation team (IGCT) might improve patients status or outcome in geriatric patients admitted to nongeriatric care wards. As a result, a new paradigm for care provision is hence currently being tested in UZ Leuven. On the cardiology wards, a geriatric comanagement care model is being investigated, supported by the IGCT [32]. In sum, to improve medication use in older adults, acute geriatric care units remain a valid setting for $\mathrm{CP}$ services.

Several limitations should be acknowledged. First, this is a qualitative research. No clinical outcomes were measured and the feedback given by the physicians was subjective, therefore response bias is not excluded. To remain as objective as possible, hypotheses were provided and most of the questions were multiple choice. Furthermore, the survey was done anonymously. Second, the response rate was not $100 \%$ so participation bias is not excluded. However a response rate of almost $60 \%$, corresponding to 45 physicians having attended the geriatric wards in the first 3 years of the program, can be considered a representative sample of the target population. Third, the survey took place in 2018 and physicians who worked at the wards between 2014 and 2018 were invited. Recall bias could hence not be excluded. However, given the overall uniform responses, we considered it to be unlikely that most respondent were equally biased. Fourth, besides physicians, other health care providers have been involved in the multidisciplinary geriatric care teams. Feedback from nurses or others such as occupational therapists could therefore also gain insights to further improve the CP program. Fifth, since the start of the program, the same clinical pharmacists were part of the CP team. Therefore, the feedback is perhaps not a reflection on the program, but more on the team dynamics and its members.

Further research is necessary to determine a high risk population within the geriatric inpatient population who would benefit the most from ward-based involvement of a clinical pharmacist, since resources to expand $\mathrm{CP}$ interventions at discharge and for all geriatric patients are limited. In addition, the body of evidence to implement clinical pharmacists in the multidisciplinary team on geriatric care wards is expanding [33]. However, there is still need for more high-level evidence to show the impact of CP services on important outcomes, such as hospital and/or emergency department readmission, quality of life and mortality [23].

\section{Conclusions}

Physician's satisfaction with the $C P$ service was very high. Clinical pharmacists on the acute geriatric wards of a large teaching hospital are perceived by physicians as time-saving and clinically relevant. The current time allocation of 0.8 FTE for 80 beds is however limited. Further optimization of the program, with implementation of medication reconciliation on admission, patient counseling and follow-up within primary care, is warranted. 


\section{Disclosure statement}

No potential conflict of interest was reported by the authors.

\section{References}

[1] Gallagher PF, O'Connor MN, O'Mahony D. Prevention of potentially inappropriate prescribing for elderly patients: a randomized controlled trial using STOPP/START criteria. Clin Pharmacol Ther. 2011;89 (6):845-854.

[2] Van der Linden L, Decoutere L, Walgraeve K, et al. Combined use of the rationalization of home medication by an adjusted STOPP in older patients (RASP) list and a pharmacist-led medication review in very old inpatients: impact on quality of prescribing and clinical outcome. Drugs Aging. 2017;34(2):123-133.

[3] El Morabet N, Uitvlugt EB, van Den Bemt BJF, et al. Prevalence and preventability of drug-related hospital readmissions: a systematic review. J Am Geriatr Soc. 2018;66(3):602-608.

[4] Klotz U. Pharmacokinetics and drug metabolism in the elderly. Drug Metab Rev. 2009;41(2):67-76.

[5] Leendertse AJ, Egberts AC, Stoker LJ, et al. Frequency of and risk factors for preventable medication-related hospital admissions in the Netherlands. Arch Intern Med. 2008;168(17):1890-1896.

[6] Andersson ML, Böttiger $Y$, Kockum $H$, et al. High prevalence of drug-drug interactions in primary health care is caused by prescriptions from other healthcare units. Basic Clin Pharmacol Toxicol. 2018;122(5):512-516.

[7] Ryan C, Ross S, Davey $P$, et al. Prevalence and causes of prescribing errors: the prescribing outcomes for trainee doctors engaged in clinical training (PROTECT) study. PLoS One. 2014;9(1):e79802.

[8] Greenhalgh T, Howick J, Maskrey N, Group EBMR. Evidence based medicine: a movement in crisis? Bmj. 2014;348:g3725.

[9] Christensen M, Lundh A. Medication review in hospitalised patients to reduce morbidity and mortality. Cochrane Database Syst Rev. 2016;2(CD008986). DOI:10.1002/14651858.CD008986.pub3

[10] Renaudin P, Boyer L, Esteve MA, et al. Do pharmacist-led medication reviews in hospitals help reduce hospital readmissions? A systematic review and meta-analysis. $\mathrm{Br} J$ Clin Pharmacol. 2016;82 (6):1660-1673.

[11] Holland R, Desborough J, Goodyer L, et al. Does pharmacist-led medication review help to reduce hospital admissions and deaths in older people? A systematic review and meta-analysis. $\mathrm{Br} J$ Clin Pharmacol. 2008;65(3):303-316.

[12] Hohl CM, Wickham ME, Sobolev B, et al. The effect of early in-hospital medication review on health outcomes: a systematic review. $\mathrm{Br} J$ Clin Pharmacol. 2015;80(1):51-61.

[13] Patterson SM, Hughes C, Kerse N, et al. Interventions to improve the appropriate use of polypharmacy for older people. Cochrane Database Syst Rev (Online). 2012;5:CD008165.

[14] Patterson SM, Cadogan CA, Kerse N, et al. Interventions to improve the appropriate use of polypharmacy for older people. Cochrane Database Syst Rev. 2014;10 (CD008165). DOI:10.1002/14651858.CD008165.pub3

[15] Johansson T, Abuzahra ME, Keller S, et al. Impact of strategies to reduce polypharmacy on clinically relevant endpoints: a systematic review and meta-analysis. Br J Clin Pharmacol. 2016;82(2):532-548.

[16] Gillespie U, Alassaad A, Henrohn D, et al. A comprehensive pharmacist intervention to reduce morbidity in patients 80 years or older: a randomized controlled trial. Arch Intern Med. 2009;169(9):894-900.

[17] Pellegrin KL, Krenk L, Oakes SJ, et al. Reductions in medication-related hospitalizations in older adults with medication management by hospital and community pharmacists: a quasi-experimental study. J Am Geriatr Soc. 2017;65(1):212-219.

[18] Johansen JS, Havnes $\mathrm{K}$, Halvorsen $\mathrm{KH}$, et al. Interdisciplinary collaboration across secondary and primary care to improve medication safety in the elderly (IMMENSE study): study protocol for a randomised controlled trial. BMJ Open. 2018;8(1):e020106.

[19] Somers A, Spinewine A, Spriet I, et al. Development of clinical pharmacy in Belgian hospitals through pilot projects funded by the government. Acta Clin Belg. 2018;1-7. DOI:10.1080/17843286.2018.1462877

[20] Kaboli PJ, Hoth AB, McClimon BJ, et al. Clinical pharmacists and inpatient medical care: a systematic review. Arch Intern Med. 2006;166(9):955-964.

[21] Walgraeve K, Van der Linden L, Flamaing J, et al. Feasibility of optimizing pharmacotherapy in heart failure patients admitted to an acute geriatric ward: role of the clinical pharmacist. Eur Geriatric Med. 2018;9(1):103-111.

[22] Van der Linden L, Hias J, Dreessen L, et al. Medication review versus usual care to improve drug therapies in older inpatients not admitted to geriatric wards: a quasi-experimental study (RASP-IGCT). BMC Geriatr. 2018;18(1):155.

[23] Van der Linden L, Hias J, Walgraeve K, et al. Clinical pharmacy services on geriatric care wards: catch 22 of implementation and research. Drugs Aging. 2018;35 (5):375-377.

[24] Hellstrom LM, Bondesson A, Hoglund P, et al. Impact of the Lund Integrated Medicines Management (LIMM) model on medication appropriateness and drug-related hospital revisits. Eur J Clin Pharmacol. 2011;67(7):741-752.

[25] Goodman S. A dirty dozen: twelve p-value misconceptions. Semin Hematol. 2008;45(3):135-140.

[26] Leek J, McShane BB, Gelman A, et al. Five ways to fix statistics. Nature. 2017;551(7682):557-559.

[27] Ravn-Nielsen LV, Duckert ML, Lund ML, et al. Effect of an in-hospital multifaceted clinical pharmacist intervention on the risk of readmission: a randomized clinical trial. JAMA Intern Med. 2018;178(3):375-382.

[28] Weeks G, George J, Maclure K, et al. Non-medical prescribing versus medical prescribing for acute and chronic disease management in primary and secondary care. Cochrane Database Syst Rev. 2016;11: CD011227.

[29] Hias J, Van der Linden L, Spriet I, et al. Predictors for unintentional medication reconciliation discrepancies in preadmission medication: a systematic review. Eur J Clin Pharmacol. 2017;73(11):1355-1377. 
[30] Cornu P, Steurbaut S, Leysen T, et al. Effect of medication reconciliation at hospital admission on medication discrepancies during hospitalization and at discharge. Int J Clin Pharm. 2012;34(1): 213-214.

[31] Koshman SL, Charrois TL, Simpson SH, et al. Pharmacist care of patients with heart failure: a systematic review of randomized trials. Arch Intern Med. 2008;168(7):687-694.
[32] Deschodt M, Van Grootven B, Jeuris A, et al. Geriatric CO-mAnagement for Cardiology patients in the Hospital (G-COACH): study protocol of a prospective before-after effectiveness-implementation study. BMJ Open. 2018;8(10):e023593.

[33] Skjot-Arkil H, Lundby C, Kjeldsen LJ, et al. Multifaceted pharmacist-led interventions in the hospital setting: a systematic review. Basic Clin Pharmacol Toxicol. 2018. DOI:10.1111/bcpt.13030 